Geopolítica(s) Revista de estudios sobre espacio y poder ISSN: 2172-3958

\title{
Las rutas de la hegemonía estadounidense en un sistema multipolar
}

María Antonia Correa Serrano (coord.) (2014) Estrategias y desafíos de Estados Unidos frente al siglo XXI. México: Editorial Itaca. 151 pp. ISBN: 978-6077957-90-4.

La política exterior estadounidense constituye un elemento de investigación tradicional en el terreno de las Ciencias Sociales y, en este sentido, la publicación de Estrategias y desafios de Estados Unidos frente al siglo XXI añade una serie de aportaciones que permiten actualizar y ampliar el grado de conocimiento sobre el protagonismo de la Casa Blanca en el contexto de un mundo interdependiente. En esta obra colectiva, María Antonia Correa reúne los trabajos de una serie de especialistas en la materia que desarrollan su labor científica en distintas sedes de la Universidad Autónoma Metropolitana de México.

El ejercicio de un liderazgo asumido por Washington en el orden mundial marca el eje transversal de la obra. Los análisis específicos de cada autor muestran, en cambio, las distintas líneas estratégicas adoptadas en múltiples escalas por la política exterior estadounidense con la pretensión de prolongar una hegemonía cuestionada por la consolidación de múltiples centros de poder en el siglo XXI. Los textos que componen el conjunto del trabajo expresan unas coordenadas geográficas concretadas por la situación subcontinental norteamericana, el nivel regional correspondiente a la zona asiática del Pacífico y, por último, la escala global.

El propósito fundamental de este trabajo consiste en subrayar los cambios y las continuidades experimentadas en la agenda internacional de Estados Unidos en las recientes décadas del siglo XXI. Este objetivo conduce hacia la identificación de los actores involucrados en la gobernanza global definida por unos escenarios de cooperación y conflictividad (p. 16). El balance entre el hipotético declive hegemónico estadounidense y las estrategias para fortalecer su liderazgo propicia un dilema explicativo en torno a las tendencias de integración, especialmente en el terreno económico, ya que la imagen de los recursos energéticos como una fuente de poder adquiere un fuerte peso explicativo en muchas de las lecciones que dividen esta publicación.

El foco de atención de los dos primeros capítulos que siguen al texto introductorio descansa en las relaciones exteriores que Washington mantiene con Canadá y México. La selección de estos países como objeto de estudio remite a una condición de continuidad geográfica, ya que Estados Unidos sólo comparte su extensa frontera terrestre con ellos. En el caso canadiense, Delia Montero examina los in- 
tercambios comerciales y los efectos derivados de la presencia creciente de China en el mercado norteamericano. Sin embargo, la autora destaca que este factor no modifica sustantivamente las relaciones por un doble motivo: las exportaciones que recibe Estados Unidos de ambos países son compatibles y la existencia de un firme compromiso en materia de seguridad frente a una posible amenaza externa (pp. 4044). Además, la afinidad cultural favorece un marco calificado de "integración silenciosa" que invita a la reciprocidad (pp. 23-27).

En el estudio de María Antonia Correa sobre la política exterior proyectada hacia México, el hilo argumental radica en el debilitamiento económico estadounidense motivado por las dinámicas globalizadoras que transforman la escena internacional en el cambio de siglo mediante el surgimiento de nuevos centros de poder (pp. 52-55). Estas modificaciones propician una serie de desafíos concretos que afectan a las relaciones de Estados Unidos con el país latinoamericano, que asume un triple papel en la geopolítica estadounidense: reserva de fuentes energéticas, garantía de seguridad fronteriza frente al narcotráfico e intermediario diplomático con el resto de América Latina (pp. 70-75). La consolidación institucional de esta dependencia remite al Tratado de Libre Comercio de América del Norte y, como indica Correa, el principal reto desde la perspectiva mexicana reside en "buscar los mecanismos para aprovechar los beneficios que este acuerdo puede otorgarle, no en términos del repliegue con Estados Unidos, sino en la generación de una plataforma para su exportación" (p. 76).

En la región asiática destaca el promedio de la tasa anual de crecimiento de la economía china, que asciende hasta un 9,7\% durante el período comprendido entre los años 1978-2005 y significa, en palabras de Fontana, "un éxito formidable en términos de la historia universal" ". Este síntoma y el ascenso de China como principal adversario de Estados Unidos en el tablero geopolítico fundamentan el capítulo firmado por Graciela Yolanda Pérez-Gavilán. En su razonamiento subyace la idea de un análisis situado del poder, que adquiere su máxima ejemplificación en el desplazamiento experimentado por el centro político-financiero desde su localización tradicional en las latitudes septentrionales del Atlántico hacia la región asiática del Pacífico. La exposición de Pérez-Gavilán sigue el itinerario marcado por las nuevas directrices estratégicas desarrolladas desde la Casa Blanca para recuperar su liderazgo en la región: la aplicación del denominado soft power ${ }^{2}$ (pp. 90-95). Este recurso supone un viraje en la política exterior regional durante el siglo XXI y coincide con la Administración de Obama, que pretende contrarrestar la progresiva deslegitimación del liderazgo estadounidense percibida durante los mandatos presidenciales de George W. Bush.

La escala global está condensada en los dos capítulos que cierran la obra. En el primero de ellos, Ana Teresa Gutiérrez muestra una especial atención por la agenda de seguridad y la redefinición de una geopolítica mundial originada tras la desaparición del bloque socialista liderado por la Unión Soviética, que permite a Estados

Josep Fontana: Por el bien del imperio. Una historia del mundo desde 1945. Barcelona: Pasado \& Presente, 2011, p. 893.

2 Este concepto alude a la capacidad adquirida por un Estado para ejercer su influencia en la escena política y lograr apoyos favorables a sus intereses mediante la práctica de estrategias persuasivas culturales, comerciales o diplomáticas. Para un estudio más detallado, véase Joseph S. Nye: Soft Power. The Means in Success in World Politics. New York: Public Affairs, 2004. 
Unidos propagar su proyecto hegemónico a través de dos figuras teóricas destacadas: por un lado, la Doctrina Brzezinski y su preferencia por la región euroasiática, que congrega a los principales competidores por el control de los recursos naturales y que representa una vía de acceso hacia la zona de Oriente Medio $^{3}$ o el continente africano (pp. 108-111); y, por otro lado, la Doctrina Kluger y la sugerencia de una nueva carrera armamentística para sostener dos conflictos bélicos de manera simultánea (pp. 111-113).

El incremento del grado de competitividad que expresan ambas propuestas es recuperado por Enrique Catalán en el último ensayo sobre las tendencias estratégicas que perfilan la política exterior de Estados Unidos. Su trabajo explora brevemente las raíces y los dispositivos que jalonan la construcción histórica de la preeminencia estadounidense. Este autor sostiene que el poder de la Casa Blanca muestra un predominio a escala planetaria desde su participación en la I Guerra Mundial (p. 133), aunque esta afirmación puede ser matizada por el repliegue de su política exterior sobre los márgenes continentales tras creación de la Sociedad de Naciones en el período de entreguerras y el antagonismo del bloque socialista liderado por el Kremlin después de 1945. La disuasión nuclear favorece la imagen de una pax americana que recorre la Guerra Fría; sin embargo, la guerra representa una variable constante que permite apuntalar o socorrer a la hegemonía de Washington "para expandir su territorio o ejercer su influencia en las regiones de su interés, siempre bajo una doble moral de aludir a su intervención como un acto civilizatorio y para preservar las instituciones del mundo libre" (p. 141).

En líneas generales, la concepción de la política internacional desarrollada por Washington coincide con un panorama continuista y su interrupción responde a la configuración de un escenario multipolar, que adquiere su máxima expresión tras la alteración geopolítica que suponen los ataques registrados el 11 de septiembre del año 2001. Esta nueva coyuntura proporciona una serie de variables que desafían la posición preponderante de Estados Unidos en el actual esquema del sistema-mundo $\mathrm{y}$, aunque Wallerstein sitúa el origen de estas vicisitudes tras el desenlace de la Guerra Fría $^{4}$, su naturaleza procede de la propia realidad cambiante del universo político-económico que impide el desarrollo de unas líneas estratégicas basadas en el criterio de la acción unilateral.

La perspectiva de unas relaciones de poder centradas en el carácter jerárquico de los Estados dentro del marco global predomina en el transcurso de la obra con mayor o menor intensidad. La principal consecuencia de recurrir a este parámetro analítico es, básicamente, la significativa omisión de las múltiples agencias no estatales - empresas transnacionales, grupos de presión, entidades financieras, conglomerados mediáticos, think tanks, organismos supranacionales, etc.- que desempeñan un papel relevante en la confección de la agenda internacional a través del despliegue de su acción exterior y de sus iniciativas particulares ${ }^{5}$.

Este topónimo puede resultar controvertido porque implica una percepción de la magnitud geográfica y en este caso la designación original de la obra.

4 Immanuel Wallerstein: "The World-System After the Cold War". Journal of Peace Research, vol. 30, núm. 1, 1993, 1-6.

5 John Agnew y Stuart Corbridge: “The new geopolitics: the dynamics of global disorder", en R. J. Johnston y P. J. Taylor (eds.) A World in Crisis? Geographical Perspectives. Oxford: Blackwell, 1989. 
En conclusión, las aspiraciones hegemónicas asumidas por la Casa Blanca prevalecen desde 1945 y explican el encadenamiento de sus estrategias en la agenda internacional, al margen de las discrepancias con sus intereses domésticos en determinadas cuestiones. Esta divergencia adquiere una notable visibilidad en las contiendas electorales ${ }^{6}$ y es un rasgo singular en la política estadounidense, que mantiene firmes sus objetivos a escala mundial a pesar del debate suscitado sobre su declive. En definitiva, la publicación de Estrategias y desafios de Estados Unidos frente al siglo XXI señala la manifestación de nuevos segmentos de investigación en un campo de estudio que permanece en constante renovación.

Mariano García de las Heras González Facultad de Ciencias Políticas y Sociología, Universidad Complutense de Madrid Email: mgarciadelasheras@ucm.es

6 Perry Anderson: "Homeland". New Left Review, núm. 81, mayo-junio 2013, 5-32. [URL: $<$ https://newleftreview.org/II/81/perry-anderson-homeland $>$. Consultado el 4 de octubre de 2017] 